Khidair A Salman BDS, CES, DSO (Prof)

Ra'ed J Sa'id

BDS, MSc (Assist Lect)

\title{
The differential diagnosis of Class III
} malocclusion in adolescents of Mosul city

\author{
Dept of Pedod, orthod, and Prev Dentistry \\ College of Dentistry, University of Mosul \\ Dept of Pedod, orthod, and Prev Dentistry \\ College of Dentistry, University of Mosul
}

\begin{abstract}
Aim: To evaluate the differential diagnosis of Angle Class III malocclusion in adolescents of Mosul city. Materials and Methods: A sample of 170 Iraqi subjects aged 12-15 years, 85 subjects with Class III malocclusion (42 males and 43 females) were selected on the basis of molar and incisor relationships. Eighty fife subjects with Class I normal occlusion (42 males and 43 females) were chosen. Lateral cephalometric radiographs were taken for each subject and thirty six measurements were determined (20 angular, 14 linear and 2 ratios). Results: There were 7 subgroups in Class III malocclusion. Pure maxillary retrognathism was the most common subgroup, which represented $31.8 \%$; whereas pure mandibular prognathism was the second subgroup with $23.5 \%$. When the lower anterior facial height (LAFH) was considered with both maxillary and mandibular position, 14 subgroups were found. The most common subgroup included subjects with retrognathic maxilla, normal mandible and normal (LAFH) with $16.5 \%$ of total sample. The second subgroup included subjects with retrognathic maxilla, normal mandible and increased (LAFH) with 15.3\%. The third subgroup included subjects with normal maxilla, prognathic mandible and normal (LAFH) which represented $10.6 \%$. Conclusion: the maxillary retrognathism is more common than mandibular prognathism in Mosul City.
\end{abstract}

Key Words: Differential diagnosis, Subgroups, Class III malocclusion.

Salman KA, Said RJ. The differential diagnosis of Class III malocclusion in adolescents of Mosul city. Al-Rafidain Dent J. 2006; 6(Sp Iss ): 92S-100S.

Received: $9 / 6 / 2005$

Accepted for Publication: 19/7/2005

\section{INTRODUCTION}

Class III malocclusion has long been viewed as one of the most severe facial deformities. Mandibular prognathism is not uncommon to find, the lower jaw projecting too far forwards, so that its fore teeth pass before those of the upper jaw, when the mouth is shut; which is attended with inconvenience and disfigure the face. ${ }^{(1)}$

The differential diagnosis has become more important during recent years as a result of refinement in orthodontic, orthopedic and surgical procedure. ${ }^{(2)}$ Accurate diagnosis of skeletal and dental components of a given malocclusion is essential in determining the proper approach and timing of treatment. ${ }^{(3)}$

Class III malocclusion is one of the most difficult anomalies to understand and treat. ${ }^{(4)}$ It is important to identify whether the etiology of Class III malocclusion is dental, functional or skeletal. If the probl- em is skeletal, it must be determined whether the cause is overdeveloped mandible, underdeveloped maxilla or combination of both. ${ }^{(5)}$

So, when treating Class III patients orthodontically whether they are growing children or mature adults, antero-posterior and vertical position of facial components as well as dental relationship must be considered so that the excess or deficiency may be treated where it actually exists. ${ }^{(6)}$

Many studies have been performed to establish the percentage of malocclusion in different countries. The prevalence of Class III malocclusion represents relatively low percentage among the population, also the prevalence is different among different ethnic groups and according to the method used in the Classification. In Iraq found that $2.4 \%$ of 253 orthodontic patients have Class III malocclusion. ${ }^{(7)}$ in a study performed in rural community, found that $6.3 \%$ 
of 268 Iraqi subjects had Class III malocclusion. ${ }^{(8)}$

The Class III malocclusion is not a homogenous entity but a mixture of various patterns of deformity and have been $\mathrm{Cl}$ - assified into groups. Sanborn ${ }^{(9)}$ divided $\mathrm{Cl}$ ass III cases according to antero-posterior position of the maxilla and mandible as determined by SNA and SNB into 4 subgroups: (Figure 1)

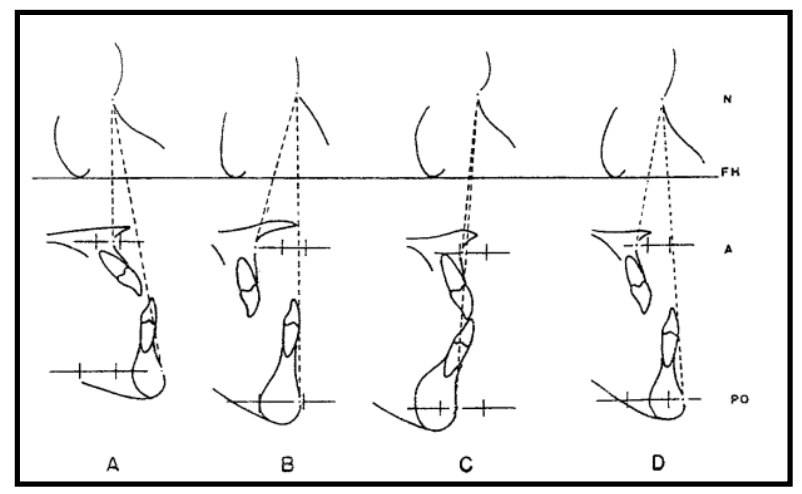

Figure (1): Main groups of Class III facial skeletal profile

Group A: Those presenting a maxilla within the normal range of prognathism and mandible beyond normal range of prognathism.

Group B: Those presenting a maxilla below normal range of prognathism and a mandible within the normal range of prognathism.

Group C: Those presenting a maxilla and a mandible within the normal range of prognathism.

Group D: Those presenting a maxilla below normal range of prognathism and a mandible beyond the normal range of prognathism.

Ellis and McNamara ${ }^{(10)}$ divided the measurements of craniofacial structures of adult Class III surgical patients into 4 horizontal components; maxillary skeletal position, maxillary dental position, mandibular dental position and mandibular skeletal position and one vertical components. When each of these five components is divided into 3 Classes: Protruded, normal and retruded, permits 243 possible subgroups; actually 69 subgroups were found.

Guyer et $a l .{ }^{(6)}$ considered the skeletal components: Maxillary skeletal position, mandibular skeletal position and vertical facial height were yielded 27 possible subgroups. They reported that the actual combinations and their percentage were different in the different age groups.

The main aim of this study was to determine the different subgroups of Class
III malocclusion by determining the different combinations of skeletal variability taking into account the antero-posterior and vertical relationships.

\section{MATERIALS AND METHODS}

The sample of this study was collected from 21 secondary schools in Mosul city, a total of 8276 students were examined. The study was carried out on 170 subjects age range between $12-15$ years: 85 subjects with Class I normal occlusion; 42 males and 43 females and 85 subjects with Class III malocclusion; 42 males and 43 females. The Criteria for Selecting Class I Control Group:

1. Full set of permanent dentition in both arches. ${ }^{(11)}$

2. Bilateral Class I molar and canine relationship, the mesiobuccal cusp of upper first molar occlude in the buccal groove of the lower first molar, the upper canine occlude in the embrasure between lower canine and lower first premolar. ${ }^{(12)}$

3. Normal overbite and overjet $2-4 \mathrm{~mm}$. ${ }^{(13)}$

4. Less than $3 \mathrm{~mm}$ crowding. ${ }^{(14)}$

5. Negligible rotations or spacing (less than $1.0 \mathrm{~mm}){ }^{(15)}$

6. Harmonious facial proportions, balanced profile with normal lip seal. ${ }^{(16)}$

7. No history of orthodontic treatment or orthognathic surgery, extensive restorative dentistry or carious teeth. ${ }^{(17)}$

8 . Good health with no major medical problems and no history of craniofacial 
trauma. ${ }^{(18)}$

9. All subjects are Iraqi in origin and live in the center of Mosul City.

Criteria for Selecting Class III Sample:

1. Full set of permanent dentition.

2. Bilateral Class III molar relationship to the extent which is slightly more than one half the width of a single cusp on each side. ${ }^{(12)}$

3. Edge to edge incisor relation and negateve overjet cases were included in this study. ${ }^{(19)}$

4. No detected functional displacement. ${ }^{(20)}$

5. No history of orthodontic treatment or orthognathic surgery. ${ }^{(21)}$

6 . No cleft or other congenital craniofacial anomalies. $^{(21)}$

7. All subjects are Iraqi in origins who live in the center of Mosul City.

Lateral cephalometric radiographs were taken for each subject under standardized conditions using Cranex Panoramic/Cephalometric imaging system (Soredex, Orion corporation, Helsinki, Finland).

The subject was set in a standing position with his head fixed by two ear rods laterally and a plastic stoppers on the bridge of the nose anteriorly so that the Frankfort horizontal plane was kept parallel to the floor. Then the radiographs were traced and the obtained measurements included SNA, SNB and lower anterior facial height (LAFH) as measured from anterior nasal spine to Menton. ${ }^{(22)}$

Analysis of Components Combination

The neutral ranges for SNA, SNB and lower anterior facial height (ANS-Me) were established from Class I normal occlusion group as the mean \pm standard deviation. Values less than neutral range indicated a retrusive position for the maxilla or mandible and short lower anterior facial height. Values greater than the neutral range indicated a protrusive position of maxilla or mandible or long lower anterior facial height. So, each value could then be classified as low, neutral or high. To evaluate the frequencies, with which various skeletal components occurred in Class III patients, an evaluation of the maxillary and mandibular skeletal components was made using the neutral ranges of SNA and SNB. Thus 9 possible subgroups may be found; however not all of them are actually exist. From the combination of the variables SNA, SNB and LAFH, 27 possible subgroups may be found; however not all of them are actually exist. ${ }^{(6)}$

\section{RESULTS}

\section{Subgroups of Class III Malocclusion According to Maxillo-mandibular Positions:}

From the 9 possible subgroups, 7 subgroups were actually found (Table 1 and Figure 2). The most prevalent subgroup included those who had pure maxillary retrognathism which represented $31.8 \%$ of the sample; the next most prevalent subgroup included those pure mandibular prognathism with $23.4 \%$ and the third subgroup had neutral maxilla and mandible with $16.5 \%$, while the forth subgroup included those with bimaxillary prognathism which formed $11.8 \%$. The fifth subgroup included those who had combined maxillary retrognathism and mandibular prognathism with $8.2 \%$. Bimaxillary retrognathism formed the sixth subgroup with $7 \%$ while the seventh subgroup included one case which had neutral maxilla and retrognathic mandible with $1.2 \%$.

Table (1): Subgroups of Class III malocclusion according to the Combination of maxillary and mandibular skeletal variables of listed in order of prevalence

\begin{tabular}{ccccc}
\hline Groups & Number & percentage & $\begin{array}{c}\text { Maxillary Skeletal } \\
\text { Position }\end{array}$ & $\begin{array}{c}\text { Mandibular Skeletal } \\
\text { Position }\end{array}$ \\
\hline I & 27 & 31.8 & Retrognathic & Neutral \\
II & 20 & 23.4 & Neutral & Prognathic \\
III & 14 & 16.5 & Neutral & Neutral \\
IV & 10 & 11.8 & prognathic & Prognathic. \\
V & 7 & 8.2 & Retrognathic & Prognathic \\
VI & 6 & 7.1 & Retrognathic & Retrognathic \\
VII & 1 & 1.2 & Neutral & Retrognathic \\
Total & 85 & 100 & - & - \\
\hline
\end{tabular}




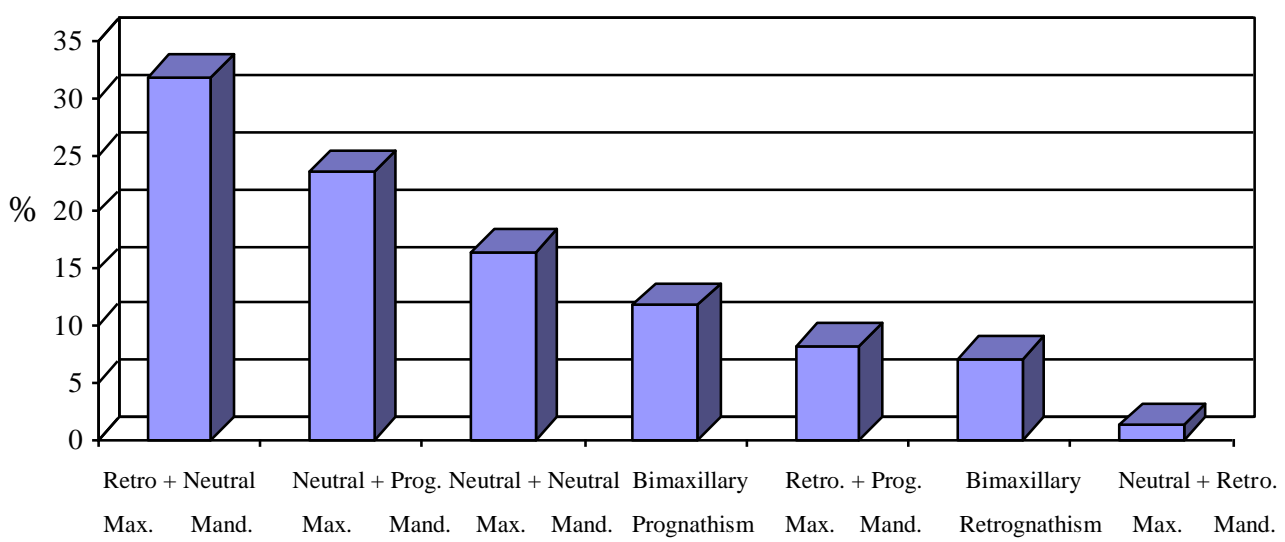

Figure (2): Subgroups of Class III Total sample according to combination of maxillary and mandibular skeletal position

Subgroups of Class III malocclusion according to Maxillo-mandibular Position and Lower Facial Height:

From 27 possible combination subgroups, 14 subgroups were actually found as shown in Table (2) and Figure (3). The most prevalent subgroup included those with pure maxillary retrognathism and neutral LAFH with $16.5 \%$. The next includeed those with pure maxillary retrognathism and long LAFH and represented $15.3 \%$ of the total sample. The third subgroup included those with pure mandibular prognathism and neutral LAFH with $13 \%$. The forth subgroup included those with neutral maxilla, neutral mandible and increased LAFH with $10.6 \%$; whereas the fifth and sixth subgroups included those with bimaxillary prognathism and neutral LAFH and those with pure mandibular prognathism and increased LAFH with $8.2 \%$ for each. The seventh subgroup included those with bimaxillary retrognathism and increased LAFH with $7 \%$. The eighth subgroup included those with neutral maxilla neutral mandible and neutral LAFH with 5.9\%; whereas the ninth subgroup included those with retrognathic maxilla, prognathic mandible and neutral LAFH with $4.7 \%$. The tenth subgroup included those with bimaxillary prognathism and increased LAFH with $3.5 \%$. The eleventh and twelfth subgroups included those pure mandibular prognathism and decreased LAFH and those with retrognathic maxilla, prognathic mandible and increased LAFH with $2.3 \%$ for each. The last 2 subgroups included those with retro- gnathic maxilla, prognathic mandible and increased LAFH and those with neutral maxilla, prognathic mandible and neutral LAFH with $1.2 \%$ for each.

\section{DISCUSSION}

Subgroups of Class III Malocclusion According to Maxillo-mandibular Positions:

Table (3) showed the comparison of the result of this study with previous studies. There were 7 possible subgroups in $\mathrm{Cl}$ ass III malocclusions in the total sample of this study.

Pure maxillary retrognathism represented the most common subgroup in the total sample which was found in $31.8 \%$, close to that found by Dietrich ${ }^{(20)}$ and also Sanborn $^{(9)}$ in his adult sample; but it was higher than that found by Jacobson et al., ${ }^{(23)}$ Ellis and McNamara, ${ }^{(10)}$ Guyer et al., ${ }^{(6)}$ Lew and Foong ${ }^{(24)}$ and Delaire. ${ }^{(25)}$ It was lower than that found by Williams and Anderson, ${ }^{(2)}$ Tom $^{(26)}$ and Mouakeh. ${ }^{(21)}$

Pure mandibular prognathism formed the second subgroup which was found in $23.4 \%$ of the total sample, close to that found by Guyer et $\mathrm{ll}^{(6)}$ and also close to Ellis and McNamara ${ }^{(10)}$ in their adult sample; but it is lower than that of Dietrich, ${ }^{(20)}$ Tom $^{(26)}$ and also Sanborn ${ }^{(9)}$ and Lew and Foong ${ }^{(24)}$ in their adult sample, it was higher than that of Jacobson et al., ${ }^{(23)}$ and Delaire $^{(25)}$ while Mouakeh ${ }^{(21)}$ found that no case with Class III malocclusion had pure mandibular prognathism among Syrian children 
Table (2): Subgroups of Class III malocclusion according to the combination of the maxillary skeletal position, mandibular skeletal position and lower vertical height listed in order of prevalence

\begin{tabular}{|c|c|c|c|c|c|}
\hline Groups & Number & percentage & $\begin{array}{c}\text { Maxillary } \\
\text { Position }\end{array}$ & $\begin{array}{c}\text { Mandibular } \\
\text { Position } \\
\end{array}$ & LAFH \\
\hline I & 14 & 16.5 & Retrognathic & Neutral & Neutral \\
\hline II & 13 & 15.3 & Retrognathic & Neutral & $\uparrow$ \\
\hline III & 11 & 13.0 & Neutral & Prognathic & Neutral \\
\hline IV & 9 & 10.6 & Neutral & Neutral & $\uparrow$ \\
\hline $\mathbf{V}$ & 7 & 8.2 & Prognathic & Prognathic & Neutral \\
\hline VI & 7 & 8.2 & Neutral & Prognathic & $\uparrow$ \\
\hline VII & 6 & 7.0 & Retrognathic & Retrognathic & $\uparrow$ \\
\hline VIII & 5 & 5.9 & Neutral & Neutral & Neutral \\
\hline IX & 4 & 4.7 & Retro & Prognathic & Neutral \\
\hline $\mathbf{X}$ & 3 & 3.5 & Prognathic & Prognathic & $\uparrow$ \\
\hline XI & 2 & 2.3 & Neutral & Prognathic & $\downarrow$ \\
\hline XII & 2 & 2.3 & Retrognathic & Prognathic & $\uparrow$ \\
\hline XIII & 1 & 1.2 & Retrognathic & Prognathic & $\downarrow$ \\
\hline XIV & 1 & 1.2 & Neutral & Retrognathic & Neutral \\
\hline Total & 85 & 100 & - & - & - \\
\hline
\end{tabular}

$\uparrow:$ Increase; $\downarrow$ : decrease.

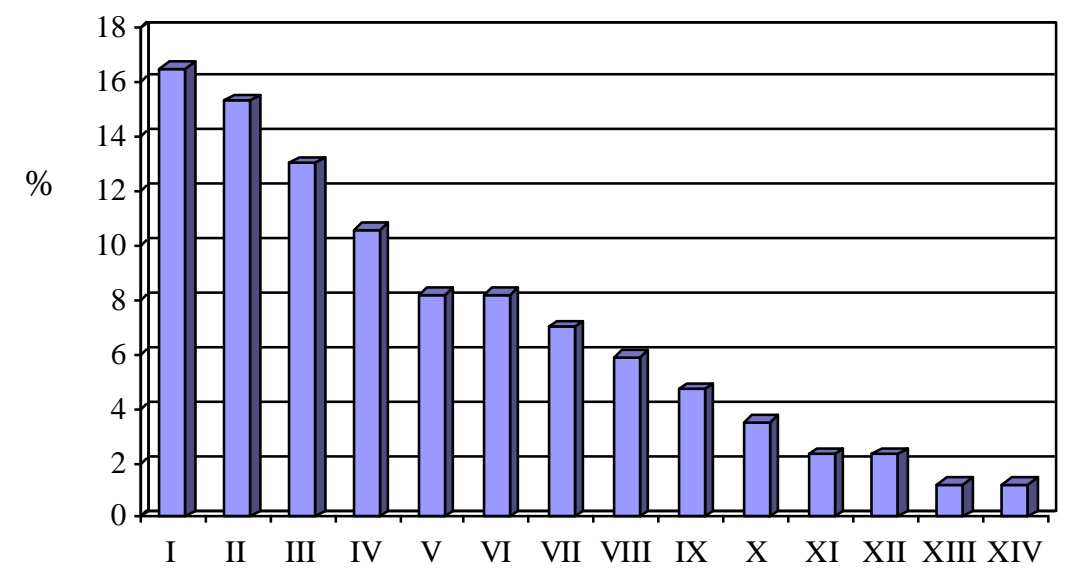

Figure (3): Subgroups of Class III total sample according to the combination of maxillary skeletal position, mandibular skeletal position and lower anterior facial height. (I. Retro. Max. Neutral Mand. Neutral LAFH II. Retro. Max. Neutral Mand. $\uparrow$ LAFH III. Neutral Max. Prog. Mand. Neutral LAFH IV. Neutral Max. Neutral Mand. $\uparrow$ LAFH V. Prog. Max. Prog. Mand. Neutral LAFH VI. Neutral Max. Prog. Mand. $\uparrow$ LAFH VII. Retro. Max. Retro. Mand. $\uparrow$ LAFH VIII. Neutral Max. Neutral Mand. Neutral LAFH IX. Retro. Max. Prog. Mand. Neutral LAFH X. Prog.. Max. Prog. Mand. $\uparrow$ LAFH XI. Neutral Max. Prog. Mand. $\downarrow$ LAFH. XII. Retro. Max. Prog. Mand. $\uparrow$ LAFH. XIII. Retro. Max. Prog.. Mand. $\downarrow$ LAFH. XIV. Neutral Max. Retro. Mand. Neutral LAFH. ) 
Table (3): Comparison of the subgroups of Class III malocclusion according to combination of maxillary and mandibular components of the present study with other studies

\begin{tabular}{|c|c|c|c|c|c|c|c|c|}
\hline $\begin{array}{c}\text { Present and } \\
\text { Previous Studies }\end{array}$ & $\begin{array}{c}\text { Age } \\
\text { (years) }\end{array}$ & $\begin{array}{c}\text { Max. } \\
\text { Retro. } \\
(\%)\end{array}$ & $\begin{array}{c}\text { Mand. } \\
\text { Prog. } \\
(\%)\end{array}$ & $\begin{array}{c}\text { Max. } \\
\text { Mand } \\
\text { Neutral } \\
(\%)\end{array}$ & $\begin{array}{c}\text { Max. } \\
\text { Mand. } \\
\text { Prog. (\%) }\end{array}$ & $\begin{array}{c}\text { Comb } \\
(\%)\end{array}$ & $\begin{array}{c}\text { Max. } \\
\text { Mand. } \\
\text { Retro. } \\
(\%)\end{array}$ & $\begin{array}{c}\text { Mand. } \\
\text { Retro. } \\
(\%)\end{array}$ \\
\hline Present Study & $12-15$ & 31.8 & 23.4 & 16.5 & 11.8 & 8.2 & 7.1 & 1.2 \\
\hline Sanborn (1955) & $16-36$ & 33.3 & 42.5 & 9.5 & - & 9.5 & 2.4 & - \\
\hline Dietrich (1970) & $\begin{array}{l}12- \\
17.5\end{array}$ & 36.8 & 30.9 & 23.5 & 1.5 & 1.5 & 5.9 & - \\
\hline $\begin{array}{l}\text { Jacobson et al. } \\
\quad(1974)\end{array}$ & $6-16$ & 8.8 & 13.3 & 59.2 & 6 & - & 8.8 & 3.8 \\
\hline $\begin{array}{c}\text { Ellis and McNamara } \\
(\mathbf{1 9 8 4})\end{array}$ & $\geq 17$ & 19.5 & 19.2 & 4.6 & 14.9 & 30.1 & 7.9 & 1.6 \\
\hline $\begin{array}{c}\text { Williams and } \\
\text { Anderson (1986) }\end{array}$ & $10-12.5$ & 41 & 33 & - & 4 & 8 & 4 & - \\
\hline Guyer et al. (1986) & $13-15$ & 22.8 & 20 & - & 11.4 & 34.3 & 5.7 & 2.92 \\
\hline Tom (1989) & $10-21$ & 40.5 & 32 & 21 & - & - & - & - \\
\hline $\begin{array}{c}\text { Lew and Foong } \\
(1993)\end{array}$ & $19-27$ & 22.5 & 38.75 & 7.5 & 11.25 & 18.75 & 1.25 & - \\
\hline Delaire (1997) & $3.5-20$ & 11.5 & 16.1 & 8 & 13.8 & 6.9 & 34.5 & 5.2 \\
\hline Mouakeh (2001) & $5-12$ & 43.5 & - & 1.45 & - & 29 & 23.2 & 2.9 \\
\hline
\end{tabular}

Mand: Mandibular; prog: Prognathism; max: Maxillary; retro: Retrognathism; Comb: Combined maxillary retrognathism and mandibular prognathism .

Dentoalveolar Class III malocclusion with neutral maxillary and mandibular position represented the third subgroup and found in $16.5 \%$ of the total sample, close to that found by Tom; ${ }^{(26)}$ but it was higher than that found by Sanborn, ${ }^{(9)}$ Ellis and McNamara, ${ }^{(10)}$ Lew and Foong, ${ }^{(24)}$ Delai$\mathrm{re}^{(25)}$ and Mouakeh, ${ }^{(21)}$ lower than that of Dietrich $^{(20)}$ and Jacobson et al., ${ }^{(23)}$ while Williams and Anderson ${ }^{(2)}$ and Guyer et $a l{ }^{(6)}$ did not find any case within this group.

Bimaxillary prognathism formed the forth subgroup with a relatively high percentage in Class III Cases which was about $11.8 \%$, close to that found by Guyer et $a l .{ }^{(6)}$ and Delaire, ${ }^{(25)}$ and also Ellis and McNamara ${ }^{(10)}$ and Lew and Foong ${ }^{(24)}$ in their adult samples; but it was higher than that found by Dietrich, ${ }^{(20)}$ Jacobson et al. ${ }^{(23)}$ and Williams and Anderson; ${ }^{(2)}$ whereas Sanbo$\mathrm{rn}^{(9)}$ and Mouakeh ${ }^{(21)}$ did not find any case with prognathic maxilla and mandible.

The combined maxillary retrognathism and mandibular prognathism formed the fifth subgroup with only $8.2 \%$ of the total sample, close to that found by Sanborn, ${ }^{(9)}$ Williams and Anderson ${ }^{(2)}$ and Delai- re, ${ }^{(25)}$ higher than that of Dietrich ${ }^{(20)}$ and lower than that found by Guyer et al. ${ }^{(6)}$ and Mouakeh $^{(21)}$ and also Ellis and McNama$\mathrm{ra}^{(10)}$ and Lew and Foong ${ }^{(24)}$ in their adult samples; whereas, Jacobson et al. ${ }^{(23)}$ and $\mathrm{Tom}^{(26)}$ found no case within this group.

Class III cases with bimaxillary retrognathism formed the sixth subgroup which formed about $7.1 \%$ of the sample, close to that found by Dietrich, ${ }^{(20)}$ Jacobson et al. ${ }^{(23)}$ Guyer et al., ${ }^{(6)}$ Williams and Anders$\mathrm{on}^{(2)}$ and also Ellis and McNamara ${ }^{(10)}$ in their adult sample. It was lower than that found by Delaire ${ }^{(25)}$ and Mouakeh; ${ }^{(21)}$ whereas it was higher than that of Sanborn ${ }^{(9)}$ and Lew and Foong ${ }^{(24)}$ in their adult samples.

The last subgroup included only one Case with normal maxilla and retruded mandible which represented $1.2 \%$ of the total sample, close to that found by Jacobson et al. ${ }^{(23)}$ Ellis and McNamara, ${ }^{(10)}$ Guyer et al., ${ }^{(6)}$ Delaire ${ }^{(25)}$ and Mouakeh; ${ }^{(21)}$ whereas, Tom ${ }^{(26)}$ and Lew and Foong ${ }^{(24)}$ found no case within this subgroup.

Subgroups of Class III Malocclusion According to Maxillo-mandibular Positions and Lower Anterior Facial Height:

There were 14 actual subgroups of 
Class III malocclusion in the total sample of this study when the LAFH is considered along with SNA and SNB. Table (4) showed the comparison of the results of this study with that of Guyer $e$ al. $^{(6)}$
The most prevalent subgroup was pure maxillary retrognathism and neutral LAFH with $16.5 \%$, this subgroup represented only $5.7 \%$ in the sample of Guyer et $a l .{ }^{(6)}$

Table (4): Comparison of the subgroups of Class III malocclusion according to the skeletal components combinations of present study with previous study

\begin{tabular}{|c|c|c|c|c|c|c|c|}
\hline \multirow{2}{*}{ Group } & \multicolumn{3}{|c|}{ Skeletal Components } & \multicolumn{2}{|c|}{ Present Study } & \multicolumn{2}{|c|}{ Guyer et al. (1986) } \\
\hline & Maxilla & Mandible & LAFH & Number & r $\%$ & Number & $\%$ \\
\hline I & Retrognathic & Neutral & Neutral & 14 & $16.5 \%$ & 2 & $5.7 \%$ \\
\hline II & Retrognathic & Neutral & $\uparrow$ & 13 & $15.3 \%$ & 5 & $14.3 \%$ \\
\hline III & Neutral & Prognathic & Neutral & 11 & $13.0 \%$ & 6 & $17.1 \%$ \\
\hline IV & Neutral & Neutral & $\uparrow$ & 9 & $10.6 \%$ & - & - \\
\hline $\mathbf{V}$ & Prognathic & Prognathic & Neutral & 7 & $8.2 \%$ & 3 & $8.6 \%$ \\
\hline VI & Neutral & Prognathic & $\uparrow$ & 7 & $8.2 \%$ & 1 & $2.9 \%$ \\
\hline VII & Retrognathic & Retrognathic & $\uparrow$ & 6 & $7.0 \%$ & 2 & $5.7 \%$ \\
\hline VIII & Neutral & Neutral & Neutral & 5 & $5.9 \%$ & - & - \\
\hline IX & Retrognathic & Prognathic & Neutral & 4 & $4.7 \%$ & 4 & $11.4 \%$ \\
\hline $\mathbf{X}$ & Prognathic & Prognathic & $\uparrow$ & 3 & $3.5 \%$ & 1 & $2.9 \%$ \\
\hline XI & Neutral & Prognathic & $\downarrow$ & 2 & $2.3 \%$ & - & - \\
\hline XII & Retrognathic & Prognathic & $\uparrow$ & 2 & $2.3 \%$ & 8 & $22.8 \%$ \\
\hline XIII & Retrognathic & Prognathic & $\downarrow$ & 1 & $1.2 \%$ & - & - \\
\hline XIV & Neutral & Retrognathic & Neutral & 1 & $1.2 \%$ & 1 & $2.9 \%$ \\
\hline $\mathbf{X V}$ & Prognathic & Neutral & $\uparrow$ & - & - & 1 & $2.9 \%$ \\
\hline XVI & Retrognathic & Neutral & $\downarrow$ & - & - & 1 & $2.9 \%$ \\
\hline Total & & & & 85 & $100 \%$ & 35 & $100 \%$ \\
\hline
\end{tabular}

Max: Maxilla; Mand: Mandible; LAFH: Lower anterior facial height; $\uparrow:$ Increased; $\downarrow$ : Decreased

The second subgroup was pure maxillary retrognathism and long LAFH and represented $15.3 \%$ of the total sample, which formed the third subgroup in the sample of Guyer et $a l .^{(6)}$ and represented $14.3 \%$. Whereas Guyer et al. ${ }^{(6)}$ found that the most common subgroup was retrognathic maxilla, prognathic mandible and increased LAFH with $22.8 \%$, which formed only $2.3 \%$ of the sample of this study, the second subgroup in their study was pure mandibular prognathism and neutral LAFH which formed $17.1 \%$; while it formed the third subgroup in this study with $13 \%$. The forth subgroup in this sample included neutral maxilla, neutral mandible and increased LAFH with $10.6 \%$; whereas no case was found within this group in the sample of Guyer et al. ${ }^{(6)}$ The fifth subgroup included bimaxillary prognathism with neutral LAFH with $8.2 \%$ close to that found by Guyer et $a l .{ }^{(6)}$ The subgroups including neutral maxilla, neutral mandible with neutral LAFH, pure mandibular prognathism with decreased LAFH and combined maxillary retrognathism and mandibular prognathism with decreased LAFH, which were found in this study, did not present in the sample of Guyer et al.; ${ }^{(6)}$ whereas the subgroups including maxillary prognathism and neutral mandible with increased LAFH and pure maxillary retrognathism with decreased LAFH were not found in this study; however they represented the last two subgroups in the sample of Guyer et al. ${ }^{(6)}$ 
The results of this study indicated that both skeletal and dento-alveolar components usually contribute to the production of most of Class III malocclusion in adolescents in a variable way. Some differences were found between the results of this study and other studies in different population, this is due to ethnic and individual variations, mean age, sample size and variation in the criteria of sample selection

\section{CONCLUSION}

Different types of Class III malocclusion exist. When the anteroposterior positions of the maxilla and mandible were considered, there were 7 possible subgroups; pure maxillary retrognathism was more common than pure mandibular prognathism.

When the lower anterior facial height (LAFH) was considered with both maxillary and mandibular position, 14 possible subgroups were found; the most common subgroup included subjects with pure maxillary retrognathism and normal (LAFH).

\section{REFERENCES}

1. Hunter J. The natural history of the human teeth. Part II. a practical treatise on the disease of the teeth intended as a supplement to the national history of those parts. London: J Johnson, 1778. Cited by: Chang HP, Kinoshita Z, Kawamoto T. Craniofacial pattern of Class III deciduous dentition. Angle Orthod. 1994; 62: 139-144.

2. Williams S, Anderson CE. The morphology of potential Class III skeletal pattern in the growing child. Am J Orthod Dentofac Orthop. 1986; 89 : 302-311.

3. Rabie ABM, Yan G. Diagnostic criteria for pseudo-Class III malocclusion. Am J Orthod Dentofac Orthop. 2000; 117: 19.

4. McGill JS, McNamara JAJr. Treatment and post-treatment effects of rapid maxillary expansion and facial mask therapy. Craniofacial groth series, the Center of Human Growth and Development. The University of Michigan, An Arbor, Michigan. 1999; 35: 123-152.

5. BaikHS, Jee SGH, Lee KJ, Oh TK. Treatment effects of Frankel functional regulator III in children with Class III mal- occlusions. Am J Orthod Dentofac Orthop. 2004; 125: 294-301.

6. Guyer EC, Ellis E, McNamara JAJr, Behrents RG. Components of Class III malocclusion in juvenile and adolescentts. Angle Orthod. 1986; 56: 7-31.

7. Agha NF, Al-Hamdany AK, Al-Khatib AR. Malocclusion assessment in orthodontically treated young Iraqis (6-18) years old. Al-Rafidain Dent J. 2002; 2 : 80-86.

8. Khamrco TY, Al-Khatib AR, Agha NF. Occlusal criteria in two Iraqi rural communities. Al-Rafidain Dent J. 2002; 2: 360-368.

9. Sanborn RT. Differences between the facial skeletal patterns of Class III malocclusion and normal occlusion. Angle Orthod. 1955; 25: 208-222.

10.Ellis E, McNamara JAJr. Components of adult Class III malocclusion. J Oral Maxillofac Surg. 1984; 42: 295-305.

11.Swierenga D, Oesterle LJ, Messersmith ML. Cephalometric values for adult Mexican Americans. Am J Orthod Dentofac Orthop. 1994; 106: 146-155.

12.Angle EH. Treatment of Malocclusion of Teeth. $7^{\text {th }}$ ed. Philadelphia, S.S. White Manufacturing Co. 1907; Pp: 40-52. Cited by: Rinchuse DJ, Rinchuse DJ. Ambiguities of Angle's Classification. Angle Orthod. 1989; 59: 295-298.

13. Kinaan BK. Overjet and overbite distribution and correlation. A comparative epidemiological English Iraqi study. $\mathrm{Br}$ J Orthod. 1986; 13: 79-86.

14.Bishara SE, Jakobsen JR. Longitudinal changes in three normal facial types. $A m$ J Orthod. 1985; 88(6): 466-502.

15.Axelsson S, Kjaer L, Bjornland T, Storhaug K. Longitudinal cephalometric standards for the neurocranium in Norwegians from 6 to 21 years of age. Eur J Orthod. 2003; 25: 185-198.

16.Hamdan AM, Rock WP. Cephalometric norms in Arabic population. J Orthod. 2001; 28: 297-300.

17.Miyajima K, McNamara JAJr, Kimura T, Murata S, Luzika T. Craniaofacial structure of Japanese and European American adults with normal occlusion. Am J Orthod Dentofac Orthop. 1996; 110: 431-438.

18. Ursi BWJS, Trotman CA, McNamara JA, Behrents RG. Sexual dimorphism in 
normal craniofacial growth. Angle Orthod. 1993; 63: 47-56.

19. Ngan P, Hu AM, Field HWJr. Treatment of Class III problems begins with differential diagnosis of anterior cross bites. Pediatr Dent. 1997; 19: 386-395.

20. Dietrich UC. Morphological variability of skeletal Class III relationships as revealed by cephalometric analysis. Trans Eur Orthod Soc. 1970; 46: 131-143.

21. Mouakeh M. Cephalometric evaluation of craniofacial pattern of Syrian children with Class III malocclusion. Am J Orthod Dentofac Orthop. 2001; 119: 640649.

22. Biggerstaff RH, Allen RC, Tuncay OC, Berkowitz J. A vertical cephalometric analysis of the human craniofacial complex. Am J Orthod. 1977; 72: 397-405.

23. Jacobson A, Evans WG, Preston CB, Sadowaski PL. Mandibular prognathism. Am J Orthod. 1974; 66: 140-171.

24. Lew KK, Foong WC. Horizontal skeletal typing in an ethnic Chinese population with true Class II malocclusion. $\mathrm{Br} J$ Orthod. 1993; 20 (1): 19-23.

25. Delaire J. Maxillary development revisited: Relevance to the orthopaedic treatment of Class III malocclusions. Eur J Orthod. 1997; 19: 289-311.

26. Tom AP. Class III malocclusion: a cephalometric study of Saudi Arabians. $\mathrm{Br} J$ Orthod. 1989; 16: 201-206. 